\title{
Dengue hemorrhagic fever complicated with transient diabetic ketoacidosis: a case report
}

\author{
Chamara Dalugama* and Indika Bandara Gawarammana
}

\begin{abstract}
Background: The increasing global prevalence of both dengue and diabetes may warrant closer observation for glycemic control and adapted fluid management to diminish the risk for a severe clinical presentation of dengue. Dengue illness is rarely known to precipitate diabetic ketoacidosis among diabetic patients. Both type 1 and type 2 diabetes increase the release of pro-inflammatory cytokines by various mechanisms and increase the risk of plasma leak in dengue fever. Acute pancreatitis is an atypical and rare presentation of dengue fever. We report a case of transient diabetic ketoacidosis in a previously well man which was challenging for the treating physician.
\end{abstract}

Case presentation: A 26-year-old previously healthy Sri Lankan Sinhalese man presented to hospital with dengue hemorrhagic fever in compensated shock. He was found to have diabetic ketoacidosis and was managed with hydration and insulin infusion. Following recovery from dengue shock, his sugars normalized and ketogenesis stopped without exogenous insulin.

Conclusions: Transient hyperglycemia with ketoacidosis, such as in our patient, has not been reported in the literature. Dengue virus inducing a transient pancreatitis during the viremic phase, however, is a possibility.

Keywords: Dengue hemorrhagic fever, Diabetic ketoacidosis, Pancreatitis

\section{Background}

Sri Lanka, as a low-income country, is experiencing a growing chronic noncommunicable disease burden such as diabetes mellitus and a high incidence rate of dengue fever; understanding the comorbidity between the two disease groups is important in patient management. Dengue fever is rarely known to precipitate diabetic ketoacidosis among patients with diabetes [1-4]. Both type 1 and type 2 diabetes increase the release of pro-inflammatory cytokines by various mechanisms and increase the risk of plasma leak in dengue fever [5, 6]. Acute pancreatitis is an atypical and rare complication of dengue fever [7-9]. During hyperglycemia in dengue fever, urine output may not be a good guide of the volume status of the patient as the patient can be polyuric even during shock. Acidosis may be contributed both by the shock and ketones and may not reflect the severity of shock. We

\footnotetext{
*Correspondence: chamaradalugama@yahoo.com

Department of Medicine, University of Peradeniya, Peradeniya, Sri Lanka
}

report a case of transient diabetic ketoacidosis in a previously well man which was diagnosed and managed during the critical phase of dengue fever and was challenging for the treating physician.

\section{Case presentation}

A 26-year-old previously healthy Sri Lankan Sinhalese man presented to the Teaching Hospital, Peradeniya with fever, arthralgia, myalgia, and headache of 3 days' duration. He complained of postural dizziness, nausea, and several episodes of vomiting since the previous day. At the same time, our patient has noticed increased frequency of passage of urine of 1 day duration. He denied any significant past medical history and no family history of diabetes mellitus among his first-degree relatives. $\mathrm{He}$ was a carpenter by profession and a nonsmoker and not an alcohol consumer.

On admission to the ward, our patient was conscious and rational, and he was complaining of thirst. He was severely dehydrated with cold, clammy peripheries and prolonged capillary refilling time. He was tachycardic 
with a pulse rate of 100 beats per minute. His blood pressure was $120 / 90 \mathrm{mmHg}$ supine and 100/90 $\mathrm{mmHg}$ on standing. He had reduced breath sounds in his right lung base. An abdominal examination revealed a marked right hypochondrial tenderness with no clinically detectable free fluid.

On admission his packed cell volume was 55. An urgent complete blood count showed a platelet count of $15 \times 10^{3}$, His hemoglobin level was $15 \mathrm{~g} / \mathrm{dL}$ and white cell count $4.15 \times 10^{6}$. His transaminases were elevated [aspartate transaminase (AST) $>$ alanine transaminase (ALT)]. His serum creatinine level was $105 \mathrm{mmol} / \mathrm{L}$ and his serum electrolytes were normal. A bedside ultrasound scan of his abdomen showed free fluid in the hepatorenal pouch. Diagnosis of dengue hemorrhagic fever was made and fluid resuscitation started. Subsequently, the diagnosis was confirmed with a positive nonstructural protein 1 (NS1) antigen test result on admission and positive antibodies for both immunoglobulin $M$ (IgM) and immunoglobulin G (IgG) on day 6 of his illness.

He was noticed to produce a considerable amount of urine contrary to the degree of dehydration. A random blood sugar test result was $296 \mathrm{mg} / \mathrm{dL}$. At the same time, his urine ketone bodies were positive and arterial blood gas (ABG) showed compensated metabolic acidosis [bicarbonate $14 \mathrm{mmol} / \mathrm{L}$, carbon dioxide partial pressure $\left(\mathrm{PCO}_{2}\right) 23 \mathrm{mmHg}$ and base excess of -11] Diagnosis of diabetic ketoacidosis was made in the same patient. His serum amylase level was $95 \mathrm{U} / \mathrm{L}$ (normal range 22 to 80 ).

Our patient was initially started on intravenous normal saline bolus of $500 \mathrm{~mL}$ and fluids tailed off guided by clinical parameters and packed cell volume. He was started on soluble insulin infusion $0.1 \mathrm{u} / \mathrm{kg}(6 \mathrm{u}$ per hour in this $60 \mathrm{~kg}$ man) and hourly blood sugar monitoring. Once his sugar level was less than $200 \mathrm{mg} / \mathrm{dL}$, he was started on sugar-containing foods (glucose, biscuits, cake, and so on) and his sugar levels were maintained between 100 and $200 \mathrm{mg} / \mathrm{dL}$. Insulin infusion rate was also tailed off according to the sugar level; we did not administer intravenous dextrose as it might have worsened the plasma leak from the dengue fever. Once his urine ketone bodies test results were negative, he was started on a regular dose of subcutaneous insulin and insulin infusion was stopped.

After recovery from dengue hemorrhagic fever, he was commenced on a routine diet and liberal fluids. After 2 days of recovering from the critical phase of dengue fever, his blood sugars were within normal limits without insulin, and his urine ketone bodies were persistently negative. His arterial blood gas showed normal bicarbonate. He was discharged on the fifth day after admission without insulin. He was reviewed in the ward 2 days after discharge and was asymptomatic. His fasting blood sugar was $98 \mathrm{mg} / \mathrm{dL}$, postprandial blood sugar was $136 \mathrm{mg} / \mathrm{dL}$, and anti-glutamic acid decarboxylase (GAD) antibodies were negative. Our patient was reviewed in the ward 5 months after his illness. He was back to his premorbid state. His glycosylated hemoglobin value was $5.8 \%$, which was in the nondiabetic range, with a fasting blood sugar value of $92 \mathrm{mg} / \mathrm{dL}$.

\section{Discussion}

We report a case of a young Sri Lankan Sinhalese man presenting with dengue shock who was found to have a transient diabetic ketoacidosis and normalization of blood sugar with the resolution of viremia. A few cases of dengue illness precipitating diabetic ketoacidosis have been reported in the literature, but transient hyperglycemia with ketosis and acidosis during dengue viremia has not been reported in the literature.

Supradish et al. reported the case of a 16-year-old Thai girl who presented in dengue shock showing signs of severe dehydration and ascites [1], but who continued to have polyuria. She was found to have hyperglycemia, ketosis, and glycosuria. Diagnosis of diabetic ketoacidosis was made. Her volume replacement was adjusted according to the degree of dehydration, and signs of volume overload were monitored closely.

One review article concluded that those who reported diabetes were two and half times as likely to have dengue hemorrhagic fever [2]. The physiopathology of dengue hemorrhagic fever suggests amplification of the immune response due to the presence of heterotypic antibodies against a serotype of the dengue virus at the time of new infection [3, 4]. Type 1 diabetes mellitus is commonly associated with autoimmunity and the immune system may be persistently activated with signs of inflammation in tissues and capillaries, and is more likely to lead to inflammation and liberation of pro-inflammatory cytokines in tissues, particularly in the endothelium, which explains the higher risk of plasma leak in dengue fever [5]. Type 2 diabetes mellitus is a metabolic disorder that changes the anatomical and physiological integrity of the endothelium due to a permanent inflammatory condition caused by activation of T-lymphocytes, which leads to the release of pro-inflammatory cytokines such as gamma interferon (IFN $\gamma$ ) and tumor necrosis factor alpha (TNF- $\alpha$ ), which increases the risk of dengue hemorrhagic fever [6].

Transient hyperglycemia with ketoacidosis, as in our patient, has not been reported in the literature. To date, there have been only a few case reports of acute pancreatitis complicating dengue fever from across the world [7-9]. Hyperlipasemia and enlarged pancreas have been known to occur in dengue fever; but acute pancreatitis is an atypical and rare presentation. In our patient his amylase level was marginally elevated but serum lipase measurement was not available. Dengue viruses inducing a transient pancreatitis or insulin resistance during the viremic phase are possible mechanisms. 


\section{Conclusions}

Dengue fever is hyperendemic in Sri Lanka. It can rarely present with various atypical endocrinologic manifestations. Both type 1 and type 2 diabetes increase the release of pro-inflammatory cytokines and increase the risk of plasma leak in dengue fever. Acute pancreatitis is a rare presentation of dengue fever. We report the first case of transient diabetic ketoacidosis during dengue hemorrhagic fever with normalization of sugars following resolution of the illness. Dengue virus inducing a transient pancreatitis or insulin resistance could be a possible mechanism.

\section{Acknowledgements}

Not applicable

\section{Funding}

Not applicable

\section{Availability of data and materials}

Data sharing not applicable to this article as no datasets were generated or analyzed during the current study.

\section{Authors' contributions}

CD and IBG examined, assessed and were involved in the management of the patient. Both authors collected and analyzed data. Both authors read and approved the final manuscript.

\section{Ethics approval and consent to participate}

Ethics approval was not obtained for the publication of this case report as this does not involve sharing of any personal details or photographs of the patient.

\section{Consent for publication}

Written informed consent was obtained from the patient for publication of this case report and any accompanying images. A copy of the written consent is available for review by the Editor-in-Chief of this journal.

\section{Competing interests}

The authors declare that they have no competing interests.

\section{Publisher's Note}

Springer Nature remains neutral with regard to jurisdictional claims in published maps and institutional affiliations.

Received: 16 June 2017 Accepted: 20 September 2017

Published online: 28 October 2017

\section{References}

1. Supradish PO, Rienmanee N, Fuengfoo A, Kalayanarooj S. Dengue hemorrhagic fever grade III with diabetic ketoacidosis: a case report. J Med Assoc Thai. 2011;94 Suppl 3:233-40.

2. Figueiredo MA, Rodrigues LC, Barreto ML, et al. Allergies and diabetes as risk factors for dengue hemorrhagic fever: results of a case control study. PLoS Negl Trop Dis. 2010;4:e699.

3. Halstead SB. The pathogenesis of dengue: molecular epidemiology in infections disease. Am J Epidemiol. 1981;114(5):632-48.

4. Kourí GP, Guzman MG, Bravo JR. Why dengue haemorrhagic fever in Cuba? An integral analysis. Trans R Soc Trop Med Hyg. 1987;81(5):821-3.

5. Brown JM, Wilson TM, Metcalfe DD. The mast cell and allergic diseases: role in pathogenesis and implications for therapy. Clin Exp Allergy. 2008:38(1):4-18.

6. Hsueh WA, Lyon CJ, Quiñones MJ. Insulin resistance and the endothelium. Am J Med. 2004;117:109-17.

7. Jusuf H, Sudjana P, Djumhana A, Abdurachman SA. DHF with complication of acute pancreatitis related hyperglycemia: a case report. Southeast Asian J Trop Med Public Health. 1998;29:367-9.
8. Chen TC, Perng DS, Tsai JJ, Lu PL, Chen TP. Dengue hemorrhagic fever complicated with acute pancreatitis and seizure. J Formos Med Assoc. 2004; 103:865-8

9. Fontal GR, Henao-Martinez AF. Dengue hemorrhagic fever complicated by pancreatitis. Braz J Infect Dis. 2011;15:490-2.
Submit your next manuscript to BioMed Central and we will help you at every step:

- We accept pre-submission inquiries

- Our selector tool helps you to find the most relevant journal

- We provide round the clock customer support

- Convenient online submission

- Thorough peer review

- Inclusion in PubMed and all major indexing services

- Maximum visibility for your research

Submit your manuscript at www.biomedcentral.com/submit 